\title{
TRIBUNAL DE CONTAS
}

\section{PENSÃO DE MONTEPIO MILITAR E MEIO SÔLDO - HE- RANÇA MILITAR - INDICAÇÃO DE HERDEIROS - REVISÃO - FILHO ADULTERINO}

- O tilho adulterino não tem direito, em grau de reversão, à herança militar.

- A indicação de herdeiros, que é peculiar ao processo de habilitação à percepção da pensão de montepio militar, se julgada legal, em decisáo judiciária, na forma do art. 30 do Dec. n. 3.695, de 6-2-39, não é suscetível de reforma por ato administrativo. Sòmente o Tribunal de Contas pode modificá-la.

- Interpretação do Dec. no 3.695 , de 6-2-39, e do Dec-1ei $n^{\circ} 426$, de 12-5-38, art 20 .

PROCESSO PG. N ${ }^{\circ} 14.379$

\section{DECISÃO}

Processo de concessão de montepio e meio sôldo a Maria Rodrigues de Amorim Neves, viúva de José Moreira das Neves, segundo tenente reformado da Polícia Militar do Distrito Federal, com despesas de Cr $\$ 2.480,00$ e Cr\$ $9.850,00$ (PG. 14.379) - O Tribunal ordenou o registro da concessão, declarando que em grau de reversão só fazem jus à mesma as filhas legítimas Maria e Luzia. Outrossim, ordenou o registro da despesa de Cr $\$ 9.850,00$ de "exercícios findos". Quanto à despesa de fôlhas classificadà à conta de "Novas Pensöes", está aritmèticamente certa. Us Srs. Ministros José Américo e Otiveira Lima registravam a concessão, simplesmente. Foi voto vencido o $\mathrm{Sr}$. Ministro Silvestre Péricles, que recusava registro, nos seguintes têrmos: "Recusei o registro da concessão, porque, além de haver a declaração expressa do oficial dé que a sua mulher abandonara o lar, me parece justo que o menor Vanderlei Moreira das Neves, reconhecido como seu filho pelo referido oficial, deve ser contemplado, desde já, na qualidáde de herdeiro, atendendo-se ainda a que é órfão de pai e mãe.

Foi o seguinte o voto proferido pelo Sr. Ministro Relator:

1. Tendo falecido, a 8 de maio de 1941 , o segundo tenente, reformado, da Policia Militar do Distrito Federal, José Moreira das Neves (fls. 2), habilitou-se a sua viúva (fls. 5) à percepção da pensão de montepio militar e do meio sôlđo que êle deixara.

2. Da "declaração de família", feita a 20 de agôsto de 1937 pelo de cujus, consta o seguinte (fls. 4):

"Casei-me civilmente com Maria Rodrigues do Amorim, que passou a assinar-se Maria Rodrigues do Amorim Neves, em 30 de outubro de 1908, a 
mesma abandonou o lar em março de 1921. Dêste consórcio nasceram as seguintes filhas: Maria Moreira das Neves em 5 de abril de 1910, e Luzia Moreira das Neves, em 21 de novembro de 1913, ambas solteiras. Tenho um filho Vanderlei Moreira das Neves, sendo sua progenitora Madalena Greco, já falecida, o qual reconheci como meu filho ao ser registrado o seu nascimento em 14 de maio de 1929".

3. O Sr. Diretor da Contadoria da Polícia Militar expediu o título provisório da pensão de montepio e do meio sôldo em favor da viúva do de cujus (fôlhas 14).

Remetido o processo, na forma do disposto no art. 30 do Decreto n. ${ }^{\circ} 3.695$, de 8 de fevereiro de 1939, ao Sr. Dr. Auditor daquela corporação, êste fêz a indicação de herdeiros seguinte (fls. 16v.):

"Indico para os devidos efeitos caber a pensão de montepio militar deixada pelo referido oficial primeiramente à sua viúva, D. Maria Rodrigues do Amorim Neves, e, na sua falta, aos seus filhos: Maria, nascida em 5 de abril de 1910; Luzia, nascida em 21 de novembro de 1913, ambas solteiras, e um filho adulterino de nome Vanderlei Moreira das Neves, nascido em 14 de maio de 1929, conforme se verifica da certidão de fls. 8 .

4. O título provisório foi transformado em definitivo, mediante apostila (fls. 14 v.), pela Diretoria da Despesa Pública.

5. O Sr. Diretor (da Segunda Diretoria do Tribunal), em parecer a fls. 27, sugere converter-se o julgamento em diligência, a fim de excluir-se da indicação de herdeiros (fls. 16 v.) o nome do menor Vanderlei, por ser filho adulterino.

6. O processo para a habilitação à percepção da pensão de montepio e meio sôldo foi simplificado pelo Decreto n.o 24.312, de 30 de maio de 1934, regulamentado pelo Decreto n. ${ }^{\circ} 3.695$, de 6 de fevereiro de 1939 , por fôrça do disposto no art. 13 do Decreto-lei $n .^{\circ} 196$, de 22 de janeiro de 1938.

Deixou de subsistir a competência conferida aos auditores militares, pelo art. $1 .^{\circ}$, § 9.', do Decreto n. 471 , de 1 de agôsto de 1891 , de acôrdo com a alteração feita pelo Decreto $n .^{\circ} 785$, de 1 de abril de 1892, para indicar "a quem caibam o montepio e meio sôldo, mencionado também, pela ordem, seus herdeiros, dada a hipótese, por lei, de haver sucessão dêsse benefício, no caso de falecimento do beneficiado".

Assim é que determina o Decreto n. ${ }^{\circ}$ 3.695, citado:

"Art. 30. O Serviço de Fundos, em seguida à inclusão dos herdeiros em fôlha de pagamento, encaminhará o processo à Auditoria competente, a fim de que esta, julgada legal a indicação feita, promova junto ao Ministério da Fazenda a habilitação definitiva dos mesmos herdeiros".

Mas o Sr. Dr. Auditor, com a sua indicação de herdeiros, homologa, em bora não o declare expressamente, a que fizera o Sr. Diretor da Contadoria da referida corporação (fls. 13), por não diferir uma da outra.

7. O menor de nome Vanderlei, por ser filho adulterino, não tem direito, em grau de reversão, à "herança militar" deixâda pelo de cujus.

8. O filho adulterino não pode ser reconhecido (Código Civil, art. 358), salvo a exceção prevista no Decreto-lei n. ${ }^{\circ} 4.737$, de 24 de setembro de 1942 — isto é, que o "filho havido pelo cônjuge fora do matrimônio pode, depois do desquite, ser reconhecido ou demandar que se declare sua filiação" (art. 1. ${ }^{\circ}$ ).

Eram equiparados aos filhos legítimos, para a percepção da pensão de montepio militar e do meio sôldo, os filhos naturais reconhecidos (Lei n. ${ }^{\circ} 632$, 
de 6 de novembro de 1899 , art. $2 .^{\circ}$ ); e, relativamente à percepção daquela pensão, apenas os filhos adotivos e os de contribuintes desquitados, nascidos posteriormente à sentença passada em julgado (Decreto-lei n. ${ }^{\circ} 196$, de 22 de junho de 1938 , arts. $80^{\circ}$ e $90^{\circ}$ ).

9. O de cujus não se desquitou; dêle separara-se a mulher (fls. 4), que vive honestamente em companhia das duas filhas (fls. 10).

10. E desñecessária, ou impraticável, a diligência sugerida pelo Senhor Diretor (fls. 27), com a qual está de acôrdo o Sr. Dr. Procurador (f1s. 27v).

Se o Tribunal julgar legal a concessão da pensão de montepio e de meio sôldo em favor da viúva do de cujuss, como se me afigura ser, basta declarar que sòmente poderão gozar de uma e de outro, em grau de reversão, as suas duas filhas legítimas.

É o meu voto.

Sala das Sessões, em 1 de junho de 1945. - A. Alvim Filho, Relator.

Entende o Sr. Ministro Oliveira Lima que os filhos adulterinos têm também direito à percepção da pensão de montepio e do meio sôldo. Foi o que declarara, em proferindo o seu voto, logo depois do meu; mas, por último, acompanhou o do Sr. Ministro José Américo, no sentido de não se apreciar agora, no Tribunal de Contas, a situação de um filho adulterino do de cujus, de vez haver sido feita à viúva dêste, exclusivamente, de acôrdo com a lei, a concessão da pensão de montepio militar e do meio sôldo.

Ambos foram contrários à diligência sugerida pelo Sr. Diretor ou que se mencionasse, na decisão, terem direito a essa concessão, em grau de reversão, apenas as filhas legitimas do de cujus.

O Sr. Ministro Silvestre Péricles recusou registro à mesma concessão, por näo se contemplar nela o referido menor.

A viúva do de cujus tem atualmente 59 anos de idade (fls. 5) e o filho adulterino dêste, nascido a 14 de maio de 1929 (fls. 8), dentro de cinco anos atingirá a maioridade, que faz cessar, para os varóes, o pagamento da pensão de montepio militar e do meio sôldo (Decreto n..$^{\circ} 846$, de 10 de janeiro de 1902 , art. $1^{\circ}$ ), salvo quanto ao da pensão de montepio, se por incapacidade física ou moral, não possam adquirir meios de subsistência (Decreto n. ${ }^{\circ} 426$, de 24 de maio de 1890 , art. $10^{\circ}$ ).

Tificitmente, poté benoficios da herança militar se reconhecido o seu direito em grau de reversão, por falecimento da viúva do de cujus ou em conseqüência dela a perder.

O pronunciamento do Tribunal nesta assentada, sôbre a situação dos herdeiros do de cujus, permite à Diretoria da Despesa Pública expedir os títulos, em grau de reversão, sem atender à indicação feita pela Diretoria da Contabilidade da Polícia Militar.

Essa indicação de herdeiros, que é peculiar ao processo de habilitação à percepção da pensão de montepio militar, se julgada legal, em decisão judiciária, na forma do art. 30 do Decreto n. 3.695 , de 6 de fevereiro de 1939, não é suscetivel de reforma por ato administrativo.

Sòmente o Tribunal de Contas pode modificá-la, à vista da competência que the é atribuída no art. $20, \S 2 .^{\circ}$, n..$^{\circ}$, letra a, do Decreto-lei n..$^{\circ} 426$, de 12 de maio de 1938.

Num caso em que se procedeu a uma justificação, para suprir a declaração de herdeiros, sendo semelhantes os efeitos da decisão da Auditoria Militar, que julga legal a indicação dos mesmos, assim se pronunciou o $\mathrm{Sr}$. Dr. Consultor Jurídico da República, em parecer emitido a 3 de junho de 1942 (in Simões Pires, Pensões Militares, apostila II, pág. 48): 
"A sentença proferida pelo Auditor, neste caso, declara a existência de uma situação jurídica; declara quais são os herdeiros do contribuinte, em virtude da prova oferecida; não se limita a certificar que se ofereceram provas de certos fatos, mas aprecia o valor das mesmas, para que seja suprida a declaração de herdeiros, inexistente ou inexata. Não é possivel, assim, admitir-se que a autoridade administrativa recuse a declaração emanada de uma autoridade judiciária, no exercício de sua atribuição privativa (Código da Justiça Militar, art. 101, letra $h$. Havendo a Auditoria julgado por sentença as justificações requeridas por D. Maria Teresa Souto de Albuquerque Lima e Dona Ana Flora Laranjeira Costa, não pode o Ministério da Fazenda pôr em dúvida a alegação, que a sentença considerou provada de ter o contribuinte deixado apenas os filhos que houve de seu casamento com a justificante. No processo de habilitação definitiva, ter-se-á de aceitar a justificação; não se poderá impugnar a sentença que a julgou. Sòmente o Tribunal de Contas, que tem a atribuição de verificar a legalidade da pensão concedida (Decreto-lei n. ${ }^{\circ} 426$, art. $\left.20, \S 2 .^{\circ}, I, a\right)$, poderá exigir nova justificação, por entender que não é satisfatória a apresentada".

Se o Tribunal de Contas deixasse de declarar que têm direito à percepção da pensão de montepio e do meio sôldo, em grau de reversão, apenaxs as filhas legítimas do de cujus, as suas cotas ficariam também diminuídas, pela coparticipação do filho adulterino, se ainda não houves atingido a maioridade, até que o mesmo Tribunal se pronunciasse sôbre a concessão, quando deferida.

E, expedindo os títulos de acôrdo com a indicação de herdeiros, a Diretoria da Despesa Pública contrariaria a própria norma que fixara a respeito.

Ela ordenou que fôssem restituídas as importâncias pagas a título de pensão de montepio civil, em beneficio de alguns menores, por serem filhos adulterinos do contribuinte, de cuja decisão negara provimento, em recurso interposto, - Sr. Diretor Geral da Fazenda Nacional.

Houve audiência do Sr. Dr. Procurador Geral da Fazenda Pública, que emitiu parecer, nestes têrmos (Diário Oficial de 26 de maio próximo findo):

"Os filhos menores, a que alude a recorrente, havidos na vigência do matrimônio do de cujus de outra mulher que não a súa espôsa legítima, de quem não estava separado legalmente, são adulterinos e não podiam e nem podem ser declarados como reconhecidos".

Pareceu-me, quando escrevi o meu voto, que não seria preciso ilustrá-lo com citações, apoiadas na doutrina ou na jurisprudência, por se tratar de matéria não controvertida em nosso direito.

Entretanto, durante a discussão, procurei novos argumentos para sustentar o ponto de vista em que me colocara, sob o império da lei.

Recorro ainda às luzes, à míngua de minha capacidade intelectuá, do Sr. Dr. Hahnemann Guimarães, que, em parecer proferido, a 7 de julho de 1942 (in Simões Pires, op. cit., pág. 18), quando exercia o cargo de consultor jurídico da República, resume òtimamente todo o assunto.

Diz êle:

“A pensão militar não tem, pròpriamente. caráter de alimentos prestados à família do militar. E antes um bem hereditário, deferido exclusivamente aos membros da família. Considerou-a o Estatuto dos Militares, por isso, a herança militar (Decretos-leis ns. 3.084, de 1 de março de 1941, art. 75, e 3.864, de 24 de novembro de 1941, art. 75 ).

A legisíação sôbre pensões militares obedece claramente à preocupação de amparar a família legítima do militar. A viúva dêste tem direito à pensão sòmente enquanto viver honestamente (Decreto n. 695 , de 28 de agôsto de 1890, art. 19). 
O amparo concedido à família natural restringe-se aos filhos naturais reconhecidos (Decreto n..$^{\circ} 632$, de 6 de novembro de 1899 , art. $3^{\circ}$ ), aos quais se acrescentaram recentemente os filhos de desquitados, nascidos posteriormente à sentença de desquite passada em julgado (Decreto-lei n. 196 , de 22 de janeiro de 1938, art. 9.0).

Nenhuma pensấo pode pretender a concubina, que a lei sôbre os acidentes de trabalho (Decreto n. 24.637 , de 10 de julho de 1934, art. $20,84 .^{\circ}$ ) e a jurisprudência, em outros casos de indenização (Arquivo Judiciário, vol. 53, pág. 145), já equipararam a espôsa.

Nenhuma pensão militar podem pretender também, e com mais forte razão, os filhos espúrios. Seria, com efeito, ilógico admitir-se que êles percebessem a pensão militar, excluindo-se a concubina, quando nada obstasse a seu casamento com o concubinário.

Se nenhum direito se atribui a esta, com maior razão deve ser negado àqueles, dada a precedência que a lei sôbre pensões militares confere à espôsa."

Nada mais tenho a acrescentar ao meu voto. - A. Alvim Filho.

\section{PENSÃO DE MONTEPIO MILITAR - CÁLCULO DA QUAN- TIA DEVIDA}

- O cálculo da pensão de montepio militar deve basear-se na tabela de vencimentos em vigor à data do falecimento, ainda que não hajam sido cobradas as últimas contribuições proporcionalmente à majoração do sôldo que venceu o de cujus.

- A beneficiária, sem prejuizo de seu direito à pensão, responde pelo pagamento da diferença das contribuiçóes.

- Interpretaça do art. 75 , \& $29^{9}$ do Dec.-1ei $n^{\circ} 3.864$, de 24-11-41 (Estatuto dos Militares).

PROCESSO PG. N. 14.156

DECISÃO

Processo de concessão de montepio militar a Daisy Costa Lima, irmã maior, solteira, de Douglas Costa Lima, 2. ${ }^{\circ}$ tenente aviador, com despesa de $\mathrm{Cr} \$ \mathbf{3 . 4 6 6 , 4 0}$ (PG. 14.156). - O Tribunal recusou registro à concessão de montepio militar, por fixar quantitativo menor que o devido. Na espécie, a pensão é igual a quinze vêzes a cota mensal das contribuições correspondentes a um dia do sôldo pela tabela que o militar percebia na atividade (Estatuto dos Militares, art. 75; Decreto-lei n. ${ }^{\circ} 196$, de 22-1-38, arts. $1 .^{\circ}$ e $\left.5 .^{\circ}\right)$. Em conseqüência, a despesa classificada a fls. à conta de "Novas Pensões" não está aritmèticamente certa.

O Sr. Ministro Relator proferiu o seguinte voto:

1. Daisy Costa Lima promoveu uma justificação, perante a Auditoria da Primeira Região Militar, com sede nesta cidade, a fim de habilitar-se à percepção da pensão de montepio militar, deixada pelo seu irmão, o segundo tenente aviador Douglas Costa Lima, que faleceu, em 18 de janeiro de 1944, na cidade de Cambuquira, Estado de Minas Gerais, em conseqüência de "desastre de aviação" (fls. 1). 
Dito oficial era solteiro (fls. 9) e não tinha filhos (fls. 24); a mãe convolou novas núpcias (fIs. 8), sendo aquela a única irmã dêle (fls. 10), e solteira (fls. 4 e 5 ).

2. Depois de julgada por sentença a justificação, em 18 de fevereiro de 1944 (fls. 4v), foi junta ao processo uma certidão do registro de óbito do refe. rido oficial, feito a 23 do mesmo mês e ano (fls. 9), da qual consta o seguinte:

"Falecido em consequiência de esmagamento da caixa craniana, com expulsão da massa encefálica - acidente de aviação; lugar do falecimento - Campo dos Afonsos, às 10 horas e 20 minutos de 18 de janeiro de 1944"'.

3. Em resposta a uma consulta, que the fizera o $\mathrm{Sr}$. Diretor do Pessoal do Ministério da Aeronáutica (fls. 12), informou o Sr. Comandante da Escola de Aeronáutica (fls. 13):

"O acidente ocorrido, na cidade de Cambuquira, Estado de Minas Gerais, no dia 18 de janeiro em curso, com o segundo tenente aviador Douglas Costa Lima e o aspirante aviador Rubens Hermes da Fonseca, não foi em serviço".

4. O Serviço de Fazenda do Ministério da Aeronáutica expediu o título provisório de pensão de montepio militar, calculada pela tabela de vencimento de que trata a Lei . $^{\circ} 287$, de 28 de outubro de 1936, na importância de Cr $\$ 433,30$ mensais (fls. 30 ), o qual foi transformado em definitivo, mediante apostila, pela Diretoria da Despesa Pública (fls. 30v).

5. O Tribunal de Contas, em sessão realizada a 18 de abril de 1944 , negou registro à concessão da pensão de montepio deixada pelo coronel intendente, da Aeronáutica, Luís Barreto Alves Ferreira, por julgar que o seu cálculo deveria obedecer à tabela de vencimentos anexada ao Decreto-lei n. 5.976 , de 10 de novembro de 1943, e não pela anterior (a que se refere a Lei n. $0^{\circ} 287$, citada), aplicada pelo Serviço de Fazenda do Ministério da Aeronáutica e Diretoria da Despesa Pública (conforme se verifica do processo, por mim requisitado).

A Diretoria da Despesa Pública pediu ao Tribunal reconsiderar essa decisão, "tendo em vista a circunstância de haver o oficial falecido em 24 de janeiro de 1944 , isto é, antes da vigência do Decreto-lei $n .^{\circ} 6.280$, de 17 de fevereiro de 1944".

Em sessão realizada a 30 de maio daquele ano, o Tribunal de Contas resolveu reconsiderar a mesma decisão, ordenando o registro da concessão, de acôrdo com o voto por mim proferido, como relator.

Do meu voto consta o seguinte:

“5. O Ministério da Aeronáutica foi criado pelo Decreto-lei n." 2.961, de 20 de janeiro de 1941, e para êle transferido o pessoal especializado de vários ministérios (art. $5^{\circ}$ ), procedendo-se ao recrutamento de acôrdo com o disposto no Decreto-1ei n. 3.810 , de 10 de novembro do mesmo ano (art. $7 .^{\circ}$ ).

6. O de cujus pertencia ao Exército e as contribuições que fizera para montepio militar eram iguais a um dia de sôldo, pela tabela de vencimento resultante da Lei $n .^{\circ} 287$, de 28 de outubro de 1936 (Decreto-lei n. ${ }^{\circ}$ 196, de 22 de janeiro de 1938 , art. $10^{\circ}$ ), devendo a pensão ser sempre igual a quinze vêzes a cota mensal das contribuiçôes, ou seja \& metade do sôldo das tabelas que serviram de base a estas contribuições (art. 5..$^{\circ}$.

Nada importa, portanto, que percebesse maior vencimento da data em que faleceu.

Seria diferente a situação se a lei dissesse que as contribuições correspondessem ao sôldo de um dia pela tabela de vencimento vigorante. 
7. Nenhuma aplicação tem à hipótese o Decreto-lei n. 6.280 , de 17 de fevereiro do corrente ano: - que regula as contribuições, para o montepio militar, dos oficiais do Exército, da Armada e Aeronáutica, em serviço ativo, a partir da data de sua promulgação, mas com a mesma redação defeituosa daquela lei, e sem se referir a outros contribuintes, enumerados no art. $10^{\circ}$, e seus 88, do Decreto-lei n. 196 , de 22 de janeiro de 1938'.

6. Não se inxocou, naquele processo, até à última decisão do Tribunal, o disposto no art. $75, \S 2 .^{\circ}$, do Estatuto dos Militares (Decreto-lei n. 3.864 , de 24 dé novembro de 1941), nestes têrmos:

"Os militares contribuirão mensalmente, para o montepio, com um dia de sôldo, deixando aos herdeiros uma pensão mensal iguâl, no mínimo, a quinze vêzes a contribuição".

Dêste modo, as pensões deixadas pelos contribuintes do montepio seriam proporcionais às contribuições feitas de acôrdo com a tabela de vencimentos em vigor na data do óbito.

Corrigiu a redação do art. $10^{\circ}$ do Decreto-lei n. 196 , de 22 de janeiro de 1938, que era a seguinte:

"As contribuições para o montepio militar dos oficiais, sub-oficiais, subtenentes e sargentos do Exército e da Armada, em serviço ativo, serão iguais a um dia de sôldo da tábela de vencimentos resultante da Lei n. 237 , de 28 de outubro de 1936".

7. Era desnecessária, pois, a providência a que alude o art. $20^{\circ}$ do Decreto-lei n. 6.280 , de 17 de fevereiro de 1944, a fim de que fộssem aumentadas as contribuiçöes para o montepio militar, e, conseqüentemente, as pensões, à vista da majoração de vencimentos, feita pelo Decreto-lei n. 5.976 , de 10 de novembro de 1943.

Dito dispositivo revogou, em parte, em relação aos oficiais, o art. $75,82 .^{\circ}$, do Estatuto dos Militares:

Ele determina:

As contribuiçós o oficia do Exército da Armada e da Aeronáutica, em serviço ativo, serão igusis a um dia de sôldo da tabela de vencimentos resultante do Decreto-lei n. 5.976 , de 10 de novembro de 1943, e o cálculo da pensão será feito de acôrdo com o \$ 2..$^{\circ}$ do art. 75 do Decreto-lei n. 3.864 , de 24 de novembro de 1941 (Estatuto dos Militares)".

Foram depois promulgados outros decretos-leis, regulando a contribuição para o montepio militar:

o de n. 7.080 , de 12 de novembro de 1944, que prescreve:

"Art. 1. O Os funcionários civis contribuintes do montepio militar, que tiveram seus vencimentos aumentados pelo Decreto-lei n..$^{\circ} .976$, de 10 de novembro de 1943 , passam a descontar para a referida instituição:

a) os que são contribuintes do montepio militar, em virtude de honras ou graduações militares concedidas anteriormente à Constituição de 10 de novembro de 1937 , um dia de sôldo correspondente ao 
pôsto ou graduação honorífica que tiverem, de acôrdo com a tabela de vencimentos militares expedida pelo Decreto-lei no 5.976; e

b) os que, sendo contribuintes do montepio militar; não possuirem honras ou graduações militares, dois terços de um dia de vencimento que tiverem pela tabela de vencimentos civis expedida pelo Decreto-lei n. ${ }^{\circ}$ 5.976";

E o de n. 7.195 , de 26 de dezembro de 1944 , que preceitua:

"Art. 1.० O pessoal da Justiça Militar, contribuinte do montepio militar, ex-vi do art. 400 do Decreto-lei n. 925 , de 2 de dezembro de 1938, e que teve seus vencimentos aumentados pelo Decreto-lei n. ${ }^{\circ} 5.976$, de 10 de novembro de 1943 , descontará para a referida instituição um dia do seu sôldo correspondente aos respectivos cargos, de acôrdo com a tabela de vencimentos militares expedida pelo citado Decreto-lei n. 5.976".

Em ambos os casos, as contribuições seriam devidas a partir da vigência do Decreto-lei n. ${ }^{\circ}$ 6.280, de 17 de fevereiro de 1944 .

8. Em resposta à consulta feita pelo $\mathrm{Sr}$. Ministro da Marinha em Aviso n. 2.035 , de 27 de novembro de 1943, se, "determinando o $\$ 2 .^{\circ}$ do art. 75 do Estatuto dos Militares que a contribuição para o montepio corresponde a um dia do sôldo, deve ser esta fixada de acôrdo com o Decreto-lei n. ${ }^{\circ} 196$, de 22 de janeiro de 1938, ou na tabela anexa ao Decreto-lei n. 5.976 , de 10 de novembro de 1943", declarou o Sr. Ministro da Fazenda, em Aviso n.” 1.342, de 26 de junho de 1944, concordar com o parecer do Sr. Dr. Procurador Geral da Fazenda (Boletim do Ministério da Marinha, de 13 de julho de 1944, página 1.956).

O Sr. Dr. Procurador Geral da Fazenda Pública opinara (ibidem) que, "aumentados os vencimentos dos militares da ativa pelo citado Decreto-lei n. 5 .976, consoante a disposição já tranșcrita do Estatuto dos Militares, aumentou, ipso facto, a contribuição para o montepio e, conseqüentemente, a pensão também aumentou".

9. Verificando-se o óbito do segundo tenente aviador Douglas Costa Lima, a 18 de janeiro de 1944 (fls. 9), quando já estava em vigor a tabela de vencimentos rriada pelo Decreto-lei n. 5.976 , de 10 de novembro de 1943 , o cálculo da pensão de montepio militar tem de basear-se nela, de acôrdo com o disposto no art. $75,82 .^{\circ}$, do Decreto-lei n. 3.864 , de 24 de novembro de 1941 (Estatuto dos Militares), ainda que não hajam sido cobradas as últimas contribuições proporcionalmente à majoração do sôldo que venceu o referido oficial.

A omissão, se houve, não pode prejudicar o direito da beneficiária, que responde apenas pelo pagamento da diferença daquelas contribuições.

10. Assim sendo, voto no sentido de negar-se registro à concessão, por ser inferior à devida.

Sala das Sessões, 5 de junho de 1945 . A. Alvim Filho, relator. 